\title{
Overexpression of BimSs3, the novel isoform of Bim, can trigger cell apoptosis by inducing cytochrome $c$ release from mitochondria ${ }^{*}$
}

\author{
Lingfeng Liu, Jinzhong Chen, Jiayi Zhang, Chaoneng Ji, Xiaomeng Zhang, \\ Shaohua Gu, Yi Xie and Yumin Mao ${ }^{\bowtie}$ \\ State Key Laboratory of Genetic Engineering, Institute of Genetics, School of Life Sciences, Fudan University, \\ Shanghai, P.R. China
}

Received: 27 November, 2006; revised: 25 April, 2007; accepted: 01 August, 2007

available on-line: 24 August, 2007

\begin{abstract}
Bim is defined as the pro-apoptotic BH3-only protein of the Bcl-2 family, which is a critical sensor and mediator in the mitochondrial-dependent apoptosis. In a previous work, we have cloned a novel transcript of Bim (GenBank accession number: AY305716) from the fetal brain cDNA, which is widely expressed in some carcinoma tissues and normal human tissues. According to the sequence analysis and the newly-defined nomenclature system of Bim isoforms (Adachi et al., 2005, Cell Death Differ 2: 192), we term it BimSs3 according to its characteristic structure. The subcellular location analysis indicated that the fused protein GFP-BimSs3 is distributed in the whole cell, mainly to the nucleus. Overexpression of BimSs3 in HEK293 cells causes apoptosis $(28.16 \pm 1.55 \%)$ compared to the negative control $(5.44 \pm 2.63 \%)$. It also causes cytochrome $c$ release from the mitochondrial fraction to the cytosolic fraction during apoptosis. Western blotting assay indicates the molecular mass of GFP-BimSs3 is approximately $31.0 \mathrm{kDa}$ (GFP: $27 \mathrm{kDa})$. Hence the open reading frame of BimSs3 may initiate at the second ATG and encodes a 36 amino-acid peptide with BH3 domain.
\end{abstract}

Keywords: BimSs3, apoptosis, cytochrome $c$

\section{INTRODUCTION}

Apoptosis plays a fundamental role in the development and maintenance of the immune system (Rathmell \& Thompson, 2002). Deficiency in immunocyte apoptosis would have striking effects on the immune system development, homeostasis and activation, which leads to a variety of diseases, such as lymphoproliferative disorder and autoimmunity (Jaruga et al., 2000; Straus et al., 1999; Navratil et al., 2006; Fadeel \& Orrenius, 2005). Numerous studies have indicated that apoptosis can be divided into two general categories: the "intrinsic" and the "extrinsic" pathways according to the signaling cascades of apoptotic events (Liu et al., 1996; Zou et al., 1997; Du et al., 2000; Putcha et al., 2002). The "intrinsic" pathway is the mitochondria-dependent pathway with characteristic of mitochondrial membrane permeabilization (MMP) and release of the cytochrome $c$ from mitochondria in apoptosis (Wakabayashi, 1999; Wang, 2001). In the healthy cells, the protein is located in the space between the inner and outer mitochondrial membranes. In mitochondria-dependent apoptosis, the apoptotic stimulus induces the release of cytochrome $c$ from the mitochondria into the cytosol where it binds to Apaf-1. The cytochrome $c$-Apaf-1 complex activates caspase-9, which then activates caspase- 3 and other downstream caspases (Cereghetti \& Scorrano, 2006).

Corresponding author: Yumin Mao, State Key Laboratory of Genetic Engineering, Institute of Genetics, School of Life Sciences, Fudan University, Shanghai, P.R. China 200433; tel: (86 21) 6564 2502; fax: (86 21) 6564 2502; e-mail: ymmao@ fudan.edu.cn

${ }^{\star}$ GenBank accession number of BimSs3: AY305716 and AAT34900.

Abbreviations: Bak, Bcl-2 homologous antagonist/killer; Bax: Bcl-2 interactive cell death susceptibility regulator; Bcl-2, B-cell lymphoma protein 2 beta isoform; BH, Bcl-2 homology domain; Bim, Bcl-2-like 11 isoform; DAPI, 4,6'-diamidino-2phenylindole; GFP, green fluorescent protein. 
The members of the Bcl-2 family have been defined as the dominant regulators in the mitochondria-dependent apoptosis (Adams \& Cory, 1998; Gross et al., 1999). Structural and functional analyses revealed that the pro-apoptotic homologues could be subdivided into the Bax subfamily and the growing BH3-only subfamily (Daniel et al., 2003; Kuwana et al., 2005). The members of the Bax subfamily, such as Bax and Bak, have been shown to be the downstream apoptotic executor and to induce mitochondria membrane permeabilization in apoptosis (Letai et al., 2002). BH3-only proteins act as mediators that link various upstream signals, including death receptors and DNA damage signaling, to the mitochondrial and the endoplasmic reticulum (ER) pathway. The BH3 domain mediates BH3-only proteins to interact with the anti-apoptotic or pro-apoptotic Bcl-2 family members and plays an essential role in apoptosis (Daniel et al., 2003). Bim, one of most important BH3-only proteins, acts as a vital sensor to initiate apoptosis in response to intracellular damage or death stimuli. Three classic isoforms BimEL, BimL and BimS were initially detected and defined as potent inducers of apoptosis (O'Connor et al., 1998). With the BH3 domain, these isoforms are able to interact with anti-apoptotic members of the multidomain Bcl-2 family such as $\mathrm{Bcl}-2, \mathrm{Bcl}-\mathrm{xL}$ and antagonize their function by releasing the sequestered Bax or Bak. They could also activate multi-domain pro-apoptotic members of the Bcl-2 family, such as Bax, Bak and cause these proteins to undergo allosteric conformation and form the lethal pore in the mitochondrial outer membrane which leads to cytochrome $c$ release and irreversible apoptosis (Letai et al., 2002; Moreau et al., 2003; Chen et al., 2005). With the DLC binding domain, BimEL and BimL are maintained in the inactive conformation through binding to the microtubule-associated dynein motor complex. BimS without the dynein binding domain is not sequestered by microtubules and induce apoptosis more potently than BimEL and BimL (Chen et al., 2004). Up to now, at least eighteen transcripts of human Bim mRNA have been detected, generated by alternative splicing (O'Connor et al., 1998; Gross et al., 1999; Mami et al., 2001; Bouillet et al., 2001; Liu et al., 2002; Idogawa et al., 2003; Chen et al., 2004). Some of them have $\mathrm{BH} 3$ domain, dynein light chain (DLC) binding domain or hydrophobic C-terminal region. These various isoforms may differ in size and pro-apoptotic activity. To facilitate the dissemination of information concerning these isoforms, Adachi and colleagues proposed the nomenclature system of Bim isoforms according to their domain structure (Adachi et al., 2005). In the newly-defined nomenclature system, Bim isoforms are divided into six groups: BimS, BimL, BimEL, BimD, BimDd and BimEDd. These group names describe the domain structure of the isoforms. Bim EL, Bim L, and Bim S represent three classical kinds of Bim isoforms which all contain the $\mathrm{BH} 3$ domain and induce cell apoptosis. BimD has no $\mathrm{BH} 3$ domain and acts as a kind of decoy. BimDd has a dynein-binding domain, whereas BimED has exon 3. Exon 3 is also the characteristic fraction of BimEL.

In a former work, we have cloned a novel transcript of Bim (GenBank accession number: AY305716) from the pre-made human fetal brain cDNA. Here we present some further work on the isoform. The comparison between its cDNA sequence and the genomic sequences (AC096670) (from NCBI website) by GeneDoc software indicates that it contains intact exon 8 (22-125 bp), exon 10 (126-250 bp), exon 11 (251-349 bp) and part of exon 2 (1-20 bp) (Fig. 2B). However, it contains an exceptional structure of two exons fused together, part of exon 2 and intact exon 8. According to its characteristic features and the nomenclature system of Bim isoforms (Adachi et al., 2005), we named it BimSs3. The flow cytometry assay and cytochrome $c$ releasing apoptosis assay confirmed its pro-apoptotic activity through the mitochondriadependent pathway. The western blotting assay indicates its molecular mass is about $4 \mathrm{kDa}$ which suggests its open reading frame initiates at the second ATG and encodes a 36 amino-acid peptide with a BH3 domain.

\section{MATERIALS AND METHODS}

Bioinformatic analysis. To identify the gene structure, multiple alignments were performed by the GeneDoc program (http://www.psc.edu /biomed/ genedoc/). The sequence of Bim isoforms from Genbank was also used. The associated software for analysis includes Gene Runner, Primer Premier 5.0.

Cell culture. The HEK293 cell line was maintained in DMEM medium (Gibco) supplemented with $10 \%$ fetal calf serum at $37^{\circ} \mathrm{C}$ in a $5 \% \mathrm{CO}_{2}$ incubator.

Subcellular location of BimSs3. The Bimfused T-vectors were digested with EcoRI and SalI and the gel-purified fragments of BimL and BimSs3 were cloned into pEGFP-C1 (Clontech). HEK293 cells were transfected with pEGFP-C1, pEGFP-C1-BimSs3 and pEGFP-C1-BimL plasmids $(1 \mu \mathrm{g} / \mathrm{ml})$ by Lipofectamine ${ }^{\mathrm{TM}} 2000$ according to the standard protocol (Invitrogen). At $24 \mathrm{~h}$ post-transfection, the cells were observed under a fluorescent microscope (Olympus). The cells transfected with pEGFP-C1-BimSs3 were fixed in $4 \%$ paraformaldehyde for $30 \mathrm{~min}$ followed by staining with $1 \mu \mathrm{g} / \mathrm{ml} \mathrm{4}$ ',6-diamidino-2-phenylindole (DAPI) for $30 \mathrm{~min}$ before observation. The fluo- 
rescence of GFP and DAPI were observed with wave length of: $488 \mathrm{~nm}, 405 \mathrm{~nm}$ for excitation and $510 \mathrm{~nm}$, $461 \mathrm{~nm}$ for emission, respectively. Then the pictures were merged with the associated software.

Flow cytometry apoptosis assay. The pEGFPC1, pEGFP-C1-BimSs3 and pEGFP-C1-BimL were transfected into HEK293 cells by Lipofectamine ${ }^{\mathrm{TM}}$ 2000 according to the standard protocol (Invitrogen) The apoptotic rate of cells was detected using APOBrDU kit (fluorescein labeled anti-BrDU antibody for labeling DNA breaks and propidium iodide (PI)/RNase A solution for counter staining the total DNA) (Becton Dickinson). The experiments were repeated at least three times.

Cytochrome $c$ releasing apoptosis assay. $\mathrm{Cy}$ tochrome $c$ releasing apoptosis assay kit was purchased from Biovision (Moutain View, CA, USA). HEK293 cells are divided into three groups and transfected with the pEGFP-C1, pEGFP-C1-BimS and pEGFP-C1-BimSs3 plasmids $(1 \mu \mathrm{g} / \mathrm{ml})$, respectively. After $18 \mathrm{~h}$ incubation at $37^{\circ} \mathrm{C}$ in a $5 \% \mathrm{CO}_{2}$ incubator, the transfected cells are divided into the mitochondrial and cytosolic fraction according to the standard protocol provided by Biovision. Purity of both fractions is determined by Western blot analysis using anti-Cox antibody (a mitochondrial protein) and calpain (a cytoplasmic protein). Cytochrome $c$ is detected in two fractions by Western blotting using anti-cytochrome $c$ antibody. Endogenous $\beta$-actin protein expression in the cells is also detected as a control of sample quantity by Western blotting using anti- $\beta$-actin antibody (Santa Cruz).

Western blotting assay. The transfected cells were washed twice with phosphate-buffered saline and lysed in $0.5 \mathrm{ml}$ lysis buffer $(50 \mathrm{mM}$ Tris at $\mathrm{pH}$ 8.0, $150 \mathrm{mM} \mathrm{NaCl}, 0.1 \% \mathrm{NP}-40,1 \mathrm{mM}$ dithiothreitol, and protease inhibitor tablets from Roche) for $15 \mathrm{~min}$ at $4^{\circ} \mathrm{C}$. After cell fractionation, the lysate was centrifuged at 14000 r.p.m. for $15 \mathrm{~min}$ at $4^{\circ} \mathrm{C}$. The supernatant was used for subsequent Western blotting assay. The proteins were subjected to SDS/ PAGE and transferred onto a nitrocellulose membrane. The membrane was blocked in 5\% non-fat milk in TBS-T $(20 \mathrm{mM}$ Tris/HCl, $137 \mathrm{mM} \mathrm{NaCl}$, and $0.1 \%(\mathrm{v} / \mathrm{v})$ Tween 20$)$ and detected with rabbit anti-human GFP polyclonal antibody (Santa Cruz) or mouse anti-cytochrome $c$ antibody (Biovision) followed by horseradish peroxidase conjugated anti-rabbit antibody (Sigma). The proteins were visualized by using enhanced chemiluminescence immunoblotting detection reagents (Amersham). The protein marker was provided by the Institute of Biochemistry and Cell Biology, SIBS, CAS.

\section{RESULTS AND DISCUSSION}

The mitochondria dependent apoptosis is tightly regulated by the $\mathrm{Bcl}-2$ family of proteins, all of which contain the Bcl-2 homology (BH) domain and function to either inhibit or promote apoptosis (Willis \& Adams, 2005). The anti-apoptotic subfamily of the Bcl-2 family is composed of multi-BH domain anti-apoptotic members such as Bcl-2, Bcl-xL and MCL-1. The pro-apoptotic members of the Bcl-2 family are further subdivided into the multidomain pro-apoptotic proteins, which include Bak and Bax, and the BH3-only proteins, which induce activation of Bak or Bax directly and indirectly (Kuwana et al., 2005). BH3-only proteins are defined as the central regulators or mediators of the mitochondrialdependent apoptosis in the pro-apoptotic members of Bcl-2 family (Willis \& Adams, 2005). Bim, one of most important BH3-only proteins, acts as a vital sensor and executor to initiate apoptosis in response to intracellular damage or death stimuli (Marani et al., 2002; Zhang et al., 2006). It counteracts and antagonizes the anti-apoptotic muti-domain proteins of the Bcl-2 family, such as Bcl-2, Bcl-xL (Cheng et al., 2001).

In a former work, we have cloned a novel mRNA transcript of Bim (AY305716) from the fetal brain cDNA library. Pre-made human normal and pathological tissues cDNA panel based PCR revealed this novel transcript is expressed widely in cancer tissues and some normal human tissues (Chen et al., 2004). The novel isoform's cDNA contains three potential ATGs (Fig. 1). Starting from the second ATG, the putative protein may com-

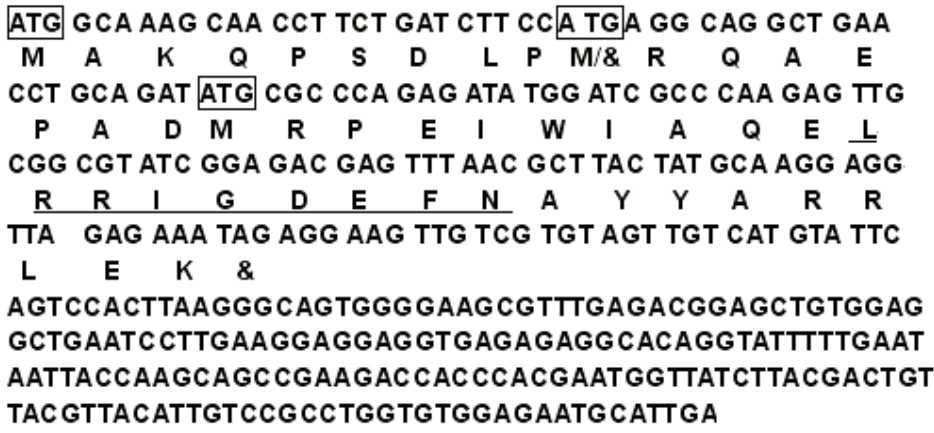

Figure 1. Nucleotide sequence and putative amino-acid sequence of the novel Bim transcript.

The potential ATG is boxed; the putative $\mathrm{BH} 3$ domain is underlined. 
prise 36 amino acids with a molecular mass of $4.424 \mathrm{kDa}$.

Exon structure and nomenclature of the novel Bim isoform

Using GeneDoc software, we performed the multiple alignments between BimS, BimSs, BimSs', BimSs2 and the novel isoform (Fig. 2). The data indicate that this novel isoform comprises the intact exon 8 (22-125 bp), exon 10 (126-250 bp) and exon 11 (251$349 \mathrm{bp}$ ) matching completely with other Bim alternative-splicing transcripts. However, it has an aberrant structure of two exons (exon 2 and exon 8) fused to- gether (The first $21 \mathrm{bp}$ fragment belongs to exon 2 and the $22-125 \mathrm{bp}$ fragment is intact exon 8 which encodes the $\mathrm{BH} 3$ domain). Hence the result suggested that the new transcript should belong to the BimS group of the newly defined nomenclature system. Based on the sequence alignment and newly determined nomenclature system of Bim, we then termed this novel isoform "BimSs3" for it contains all the same exons of BimSs' except its incomplete exon 2.

\section{Subcellular location of human BimSs3}

Through fluorescent microscopy, the EGFPBimSs3 fusion protein was found to distribute to the

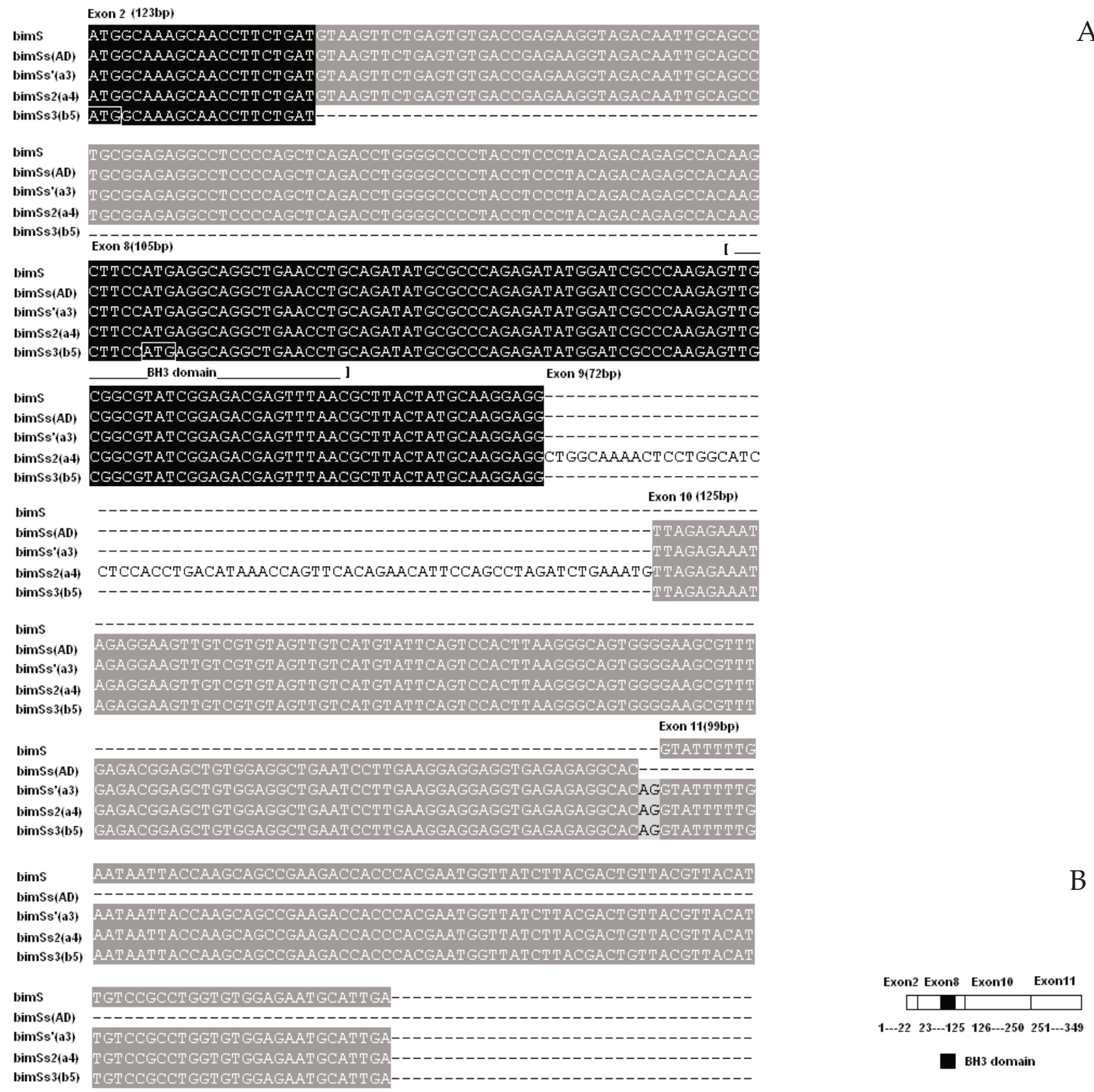

Figure 2. Sequence analysis of BimSs3.

(A) Multiple sequence analysis of Bim isoforms: BimS, BimSs, BimSs', BimSs1, BimSs2 and BimSs3. The exon starting site and its nucleotide number are marked on the top of every sequence. (B) Diagram of the exon structure of BimSs3. 

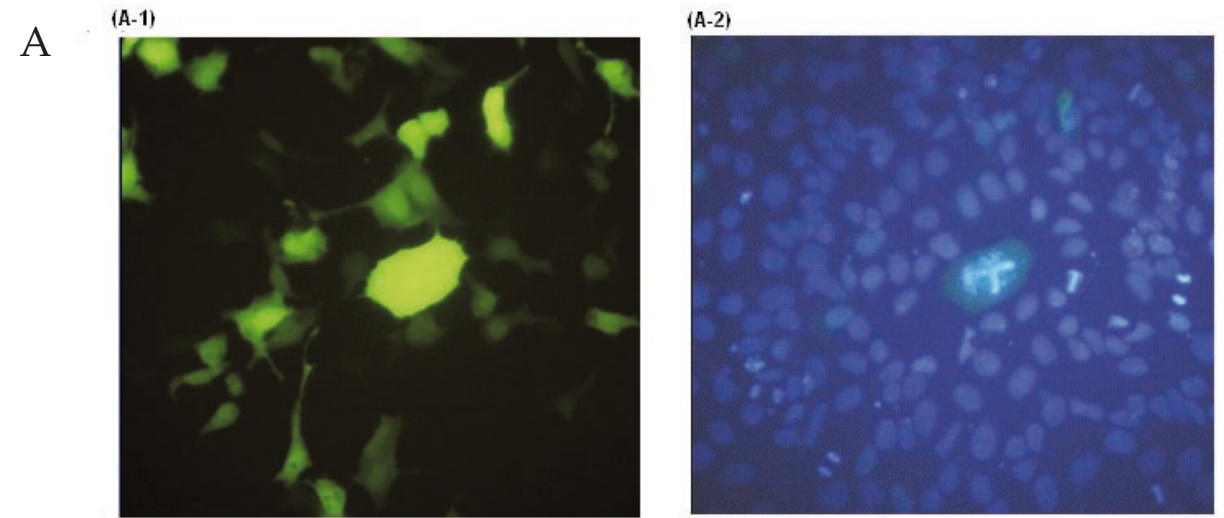

(A-3)

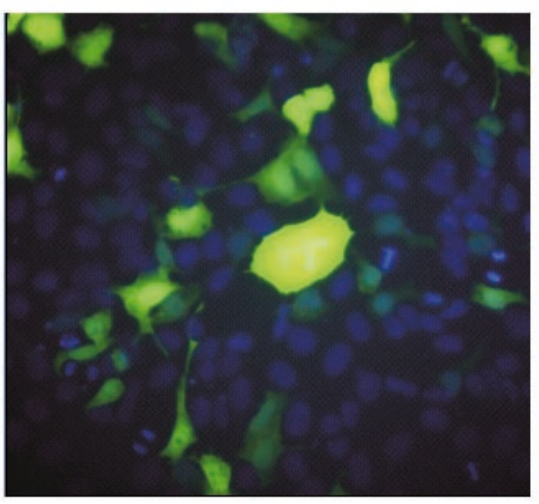

B

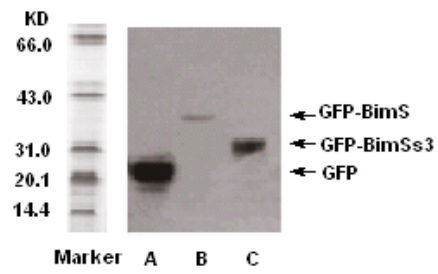

Figure 3A. Subcellular location analysis of BimSs3.

A. pEGFP-C1; B. pEGFP-C1-BimS; C. pEGFP-C1-BimSs3). The HEK293 cells expressing GFP-BimSs3 were detected using fluorescent microscopy (nuclei stained by DAPI). (A-1) GFP-Bim (green fluorescence); (A-2) nuclei (blue fluorescence); (A-3) merged pictures of (A-1 and A-2).

Figure 3B. Western blotting assay.

whole cell, mainly to the nucleus (Figs. 3A-1, A-2, A3). It is different from GFP-BimL which is known to mainly localize in the cytoplasm (Chen et al., 2004). This may be due to its putative peptide without the dynein light chain (DLC) binding domain.

To confirm the expression of GFP-fused protein, the transfected cells were lysed and detected by Western blotting using anti-GFP antibody. The immunoblotting assay indicated that the panel of BimSs3 is localized between the panels of GFP and GFP-BimS. According to the marker, the molecular mass of GFP-BimSs3 was approx. $31 \mathrm{kDa}$. Hence the molecular mass of the putative BimSs3 might be $4 \mathrm{kDa}$ containing about 30-40 amino acids (Fig. 3B). However, there is no significant ORF in mRNA of
BimSs3 due to its incomplete exon 2 and intact exon 8 fusing together. Through analysis of its sequence and putative molecular mass, we predicted the genuine ORF of BimSs3 might start at the second ATG and contain 108 nucleotides (Fig. 1).

\section{Apoptosis detection}

Under the microscope, the cells transfected with pEGFP-C1-BimSs3 presented poor growth status with many dying cells floating in the culture medium just like the cells transfected with pEGFPC1-BimS (Fig. 4A-1, A-2). This suggests that this novel isoform of Bim might also induce apoptosis. Flow cytometry assay using an APO-BrDU kit was 
A
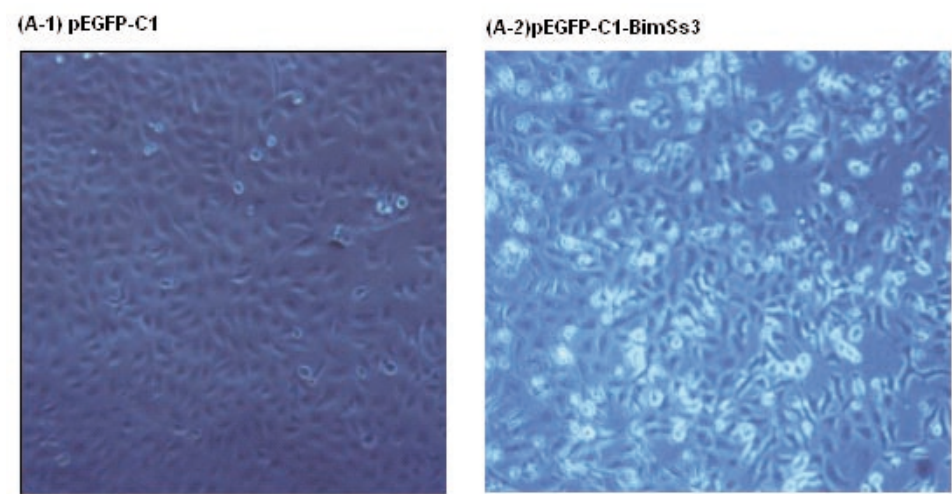

(A-3)pEGFP-C1-Bims

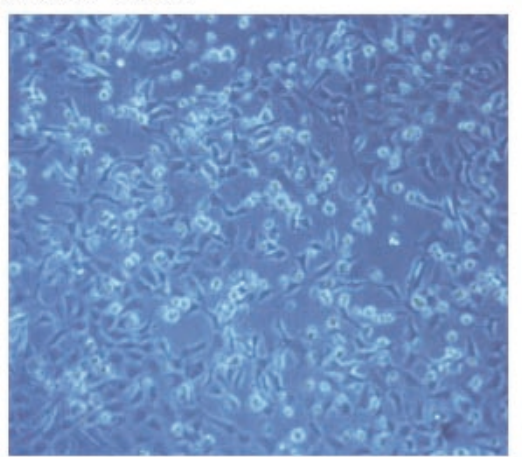

B

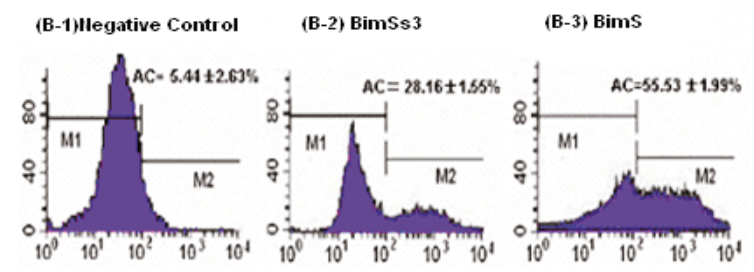

AC: apoptosis rate of cell

Figure 4. BimSs3 induces apoptosis in HEK293 cells.

A. Optical microscope image. The HEK293 cells were divided into three groups and transfected with pEGFP-C1, pEGFP-C1-BimSs3 and pEGFP-C1-BimS, respectively. After $24 \mathrm{~h}$ incubation, the cells were observed under the optical microscope. B. Flow cytometry apoptosis analysis. The HEK293 cells were terated as above except that after $24 \mathrm{~h}$ incubation, the cells were submitted to flow cytometry apoptosis analysis using APO-BrDU kit..

carried out to detect apoptosis. Compared with the negative control of plasmid pEGFP-C1 (Fig. 4B-1: $5.44 \pm 2.63 \%)$, it presented significant pro-apoptotic activity (Fig. 4B-2: $28.16 \pm 1.55 \%$ ), although its proapoptotic activity is weaker than BimS (Fig. 4B-3: $55.53 \pm 1.99 \%)$. Experiments were performed in triplicate and the representative results are shown.

To gain insight into the intracellular function of BimSs3, we turned to the cytochrome $c$ releasing apoptosis assay to detect whether its pro-apoptotic activity is associated with the mitochondria during cell apoptosis. During apoptosis,
Bim isoforms act as mediators and triggers to activate Bak/Bax which in turn form the lethal pore in the outer membrane of mitochondria and lead to release of the cytochrome $c$ from mitochondria. So in the cells undergoing mitochondria-dependent apoptosis, cytochrome $c$ can be detected both in the mitochondrial fraction and the cytosolic fraction, mainly in the cytosol, while in healthy cells, cytochrome $c$ can only be detected in the mitochondria. Using cytochrome $c$ releasing detection kit, the transfected cells were divided into the mitochondrial fraction and the cytosolic fraction. 


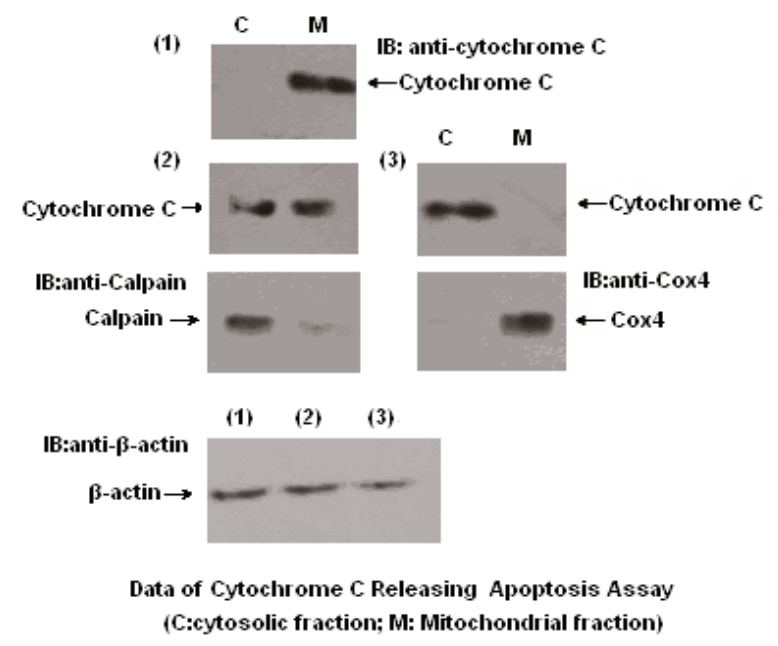

Figure 5. Cytochrome $c$ releasing apoptosis assay. (1) Negative control (the HEK293 cell transfected with pEGFP-C1); (2) The HEK293 cells transfected with pEGFPC1-BimSs3; (3) The HEK293 cells transfected with pEGFPC1-BimS. Western blot analysis using anti-Cox and anticalpain antibody were carried out to confirm purity of two fractions. The endogenous $\beta$-actin protein was also detected by anti- $\beta$-actin antibody to provide loading quantity controls.

Purity of both fractions was confirmed by Western blot analysis through detecting the distribution of the Cox (a mitochondrial protein) and calpain (a cytoplasmic protein) in the two fractions by immunoblotting assay using Cox antibody and calpain antibody. In the cells transfected with pEGFP-C1BimSs3, cytochrome $c$ can be detected in the two fractions, mainly in the cytosol. In the cells transfected with pEGFP-C1, cytochrome $c$ distributed only to mitochondrial fraction. In the cells transfected with pEGFP-C1-BimS, cytochrome $c$ mainly localized in the cytosolic fraction (Fig. 5). The result clearly indicated overexpressing BimSs3 in the cells was able to induce cytochrome $c$ release from mitochondria to the cytosol during apoptosis which was consistent with the current knowledge that Bim induced apoptosis through a mitochondria-dependent pathway.

In summary, we have cloned a novel transcript of Bim from the fetal brain cDNA and characterized its pro-apoptotic activity through flow cytometry apoptosis assay and the cytochrome $c$ releasing apoptosis assay. Based on the multiple sequence alignment and the newly-defined nomenclature system of Bim isoforms, we term it BimSs3 according to its characteristic structure. Western blotting assay indicates the molecular mass of BimSs3 is about $4 \mathrm{kDa}$. The open reading frame of BimSs3 may initiate at the second ATG and encode a 36 amino-acid peptide with a $\mathrm{BH} 3$ domain. Hence
BimSs3 is newly-defined BH3-only protein of Bcl-2 family. Further studies will be carried out to determine the potential molecular mechanisms in the BimSs3-mediated apoptosis.

\section{Acknowledgements}

We gratefully acknowledge the financial support from state 863 project (grant number: 2003AA221020) and major program of Nature Science Foundation of China (No. 10490193).

\section{REFERENCES}

Adachi M, Zhao X, Imai K (2005) Nomenclature of dynein light chain-linked BH3-only protein Bim isoforms. Cell Death Differ 2: 192-193.

Adams JM, Cory S (1998) The Bcl-2 protein family: arbiters of cell survival. Science 5381: 1322-1326.

Cereghetti GM, Scorrano L (2006) The many shapes of mitochondrial death. Oncogene 34: 4717-4724.

Chen D, Zhou Q (2004) Caspase cleavage of BimEL triggers a positive feedback amplification of apoptotic signaling. Proc Natl Acad Sci 5: 1235-1240.

Chen JZ, Ji CN, Gu SH, Li JX, Zhao EP, Huang Y, Huang L, Ying K, Xie Y, Mao YM (2004) Over-expression of Bim alpha3, a novel isoform of human Bim, result in cell apoptosis. Int J Biochem Cell Biol 8: 1554-1561.

Chen L, Willis SN, Wei A, Smith BJ, Fletcher JI, Hinds MG, Colman PM, Day CL, Adams JM, Huang DC (2005) Differential targeting of prosurvival Bcl-2 proteins by their BH3-only ligands allows complementary apoptotic function. Mol Cell 3: 393-403.

Cheng EH, Wei MC, Weiler S, Flavell RA, Mak TW, Lindsten T, Korsmeyer SJ (2001) BCL-2, BCL-X(L) sequester $\mathrm{BH} 3$ domain-only molecules preventing $\mathrm{BAX}$ - and BAK-mediated mitochondrial apoptosis. Mol Cell 3: 705-711.

Cory S, Huang DC, Adams JM (2003) The Bcl-2 family: roles in cell survival and oncogenesis. Oncogene 53: 8590-8607.

Daniel PT, Schulze-Osthoff K, Belka C, Guner D (2003) Guardians of cell death: the Bcl-2 family proteins. Essays Biochem 39: 73-88.

Du C, Fang M, Li Y, Li L, Wang X (2000) Smac, a mitochondrial protein that promotes cytochrome c-dependent caspase activation by eliminating IAP inhibition. Cell 102: 33-42.

Fadeel B, Orrenius S (2005) Apoptosis: a basic biological phenomenon with wide-ranging implications in human disease. J Intern Med 6: 479-517.

Gross A, McDonnell JM, Korsmeyer SJ (1999) BCL-2 family members and the mitochondria in apoptosis. Genes Dev 15: 1899-1911.

Heath-Engel HM, Shore GC (2006) Mitochondrial membrane dynamics, cristae remodeling and apoptosis. Biochim Biophys Acta 5: 549-560.

Idogawa M, Adachi M, Minami T, Yasui H, Imai K (2003) Overexpression of BAD preferentially augments anoikis. Int J Cancer 2: 215-223.

Jaruga E, Skierski J, Radziszewska E, Sikora E (2000) Proliferation and apoptosis of human T cells during replicative senescence - a critical approach Acta Biochim Polon 47: 293-300. 
Kuwana T, Bouchier-Hayes L, Chipuk JE, Bonzon C, Sullivan BA, Green DR, Newmeyer DD (2005) BH3 domains of $\mathrm{BH} 3$-only proteins differentially regulate Baxmediated mitochondrial membrane permeabilization both directly and indirectly. Mol Cell 4: 525-535.

Letai A, Bassik MC, Walensky LD, Sorcinelli MD, Weiler S, Korsmeyer SJ (2002) Distinct BH3 domains either sensitize or activate mitochondrial apoptosis, serving as prototype cancer therapeutics. Cancer Cell 2: 183-192.

Liu X, Kim CN, Yang J, Jemmerson R, Wang X (1996) Induction of apoptotic program in cell-free extracts: requirement for dATP and cytochrome c. Cell 86: 147157.

Liu JW, Chandra D, Tang SH, Chopra D, Tang DG (2002) Identification and characterization of Bim gamma, a novel proapoptotic BH3-only splice variant of Bim. Cancer Res 62: 2976-2981.

Mami U, Miyashita T, Shikama Y, Tadokoro K, Yamada M (2001) Molecular cloning and characterization of six novel isoforms of human Bim, a member of the proapoptotic Bcl-2 family. FEBS Lett 509: 135-141.

Marani M, Tenev T, Hancock D, Downward J, Lemoine NR (2002) Identification of novel isoforms of the BH3 domain protein Bim which directly activate Bax to trigger apoptosis. Mol Cell Biol 22: 3577-3589.

Moreau C, Cartron PF, Hunt A, Meflah K, Green DR, Evan G, Vallette FM, Juin P (2003) Minimal BH3 peptides promote cell death by antagonizing anti-apoptotic proteins. J Biol Chem 21: 19426-19435.

Navratil JS, Liu CC, Ahearn JM (2006) Apoptosis and autoimmunity. Immunol Res 36: 3-12.

O'Connor L, Strasser A, O'Reilly LA, Hausmann G, Adams JM, Cory S, Huang DC (1998) Bim: a novel member of the Bcl-2 family that promotes apoptosis. EMBO J 17: 384-395.

Putcha GV, Harris CA, Moulder KL, Easton RM, Thompson CB, Johnson EM (2002) Intrinsic and extrinsic path- way signaling during neuronal apoptosis: lessons from the analysis of mutant mice. J Cell Biol 157: 441-453.

Rathmell JC, Thompson CB (2002) Pathways of apoptosis in lymphocyte development, homeostasis, and disease. Cell 109: 97-107.

Strasser A, Harris AW, Huang DC, Krammer PH, Cory S (1995) Bcl-2 and Fas/APO-1 regulate distinct pathways to lymphocyte apoptosis. EMBO J 24: 6136-6147.

Straus SE, Sneller M, Lenardo MJ, Puck JM, Strober W (1999) An inherited disorder of lymphocyte apoptosis: the autoimmune lymphoproliferative syndrome. Ann Intern Med 130: 591-601.

Wakabayashi T (1999) Structural changes of mitochondria related to apoptosis: swelling and megamitochondria formation. Acta Biochim Polon 46: 223-237.

Wang X (2001) The expanding role of mitochondria in apoptosis. Genes Dev 15: 2922-2933.

Wei MC, Zong WX, Cheng EH, Lindsten T, Panoutsakopoulou V, Ross AJ, Roth KA, MacGregor GR, Thompson CB, Korsmeyer SJ (2001) Proapoptotic BAX and BAK: a requisite gateway to mitochondrial dysfunction and death. Science 5517: 624-626.

Willis SN, Adams JM (2005) Life in the balance: how BH3only proteins induce apoptosis. Curr Opin Cell Biol 6: 617-625.

Zhang J, Chen J, Liu L, Ji C, Gu S, Ying K, Mao Y (2006) Different gene expression profiles of AD293 and HEK293 cell lines that show contrasting susceptibility to apoptosis induced by overexpression of Bim L. Acta Biochim Polon 53: 525-530.

Zou H, Henzel WJ, Liu X, Lutschg A, Wang X (1997) Apaf1 , a human protein homologous to $C$. elegans CED-4, participates in cytochrome $c$-dependent activation of caspase-3. Cell 90: 405-413. 